\title{
THE ACHIEVEMENTS AND LIMITATIONS OF NEUROLOGIC SURGERY*
}

\author{
CHARLES H. FRAZIER, M.D., Sc.D. \\ Surgeon to the University Hospital \\ PHILADELPHIA
}

In my lifetime, the history of neurologic surgery has been written, and the most important events have occurred in half that time. In limiting the development of this special field to this period, I am not unfamiliar with the fact that trephination was an accepted surgical procedure years before the days of Hippocrates, the Father of Medicine, when the Egyptians trephined the skull for migraine and epilepsy, and that in the second century, Galen, whose favorite field of investigation was the nervous system, advocated sundry operations for injuries to the brain. He was familiar with the clinical picture of cord compression and recommended operation for its relief. While from Galen's time to the days of modern medicine, there have been isolated instances of operation, dealing with the nervous system, mostly for the relief of traumatic lesions, the growth and development of neurosurgery along broad lines and in an ever-widening zone of lesions did not occur until our own day; until the indications for surgical interference so multiplied as to command the attention of those who could give it their exclusive time and thought. Thus, in time, neurosurgery became recognized as a surgical specialty.

In passing so hastily from Galen's to our own time, we should not forget that Broca (1824-1880) has been acknowledged as the founder of modern surgery of the brain. Broca was the first to trephine for the evacuation of cerebral abscess, which had been diagnosed by his theory of localization of function. His discovery of the center of articulate speech-Broca's region-in the third left frontal convolution laid the foundation for cerebral localization. But I have always pictured the era of surgical neurology as beginning with the work of Sir Victor Horsley. How fortunate it was that the pioneer in this field should have embodied all qualifications that even now we conceive as ideal: he was the experimentalist, the neurologist, the surgeon, all in one. If we were to outline a course in preparation for the practice of surgical neurology, we could do no better than to use Horsley's life and activities as the prototype. His fundamental knowledge of neurology, his enthusiastic pursuits in the experimental laboratory, especially in brain localization, his ingenuity in matters of surgical technic were the foundation stones of his brilliant career.

\footnotetext{
* Read before the Iowa State Medical Society, Des Moines, May 12, 1921.
} 
In 1886, Horsley performed the first successful operation for the removal of brain tumor, and from that time on, brain tumors have been one of the larger, if not the largest, problems of the neurologic surgeon. The mechanics of cranial exploration have been mastered; but the management of the individual case after the cranial cavity has been opened taxes the resources of the operator, and to carry it to a successful issue inplies an intimate knowledge of the causes of increased intracranial pressure and the manner of dealing with them, of the sources of hemorrhage and how to control it, of the naked eye appearance of normal and pathologic brain tissue, of the limitations of surgical intervention and the recognition at the operating table of what constitutes an operable and what an inoperable lesion.

We have outlived what used to be called the "expectant treatment" of tumors, a screen behind which the physician concealed his inability to make a diagnosis. Contrary to the general impression, gummas of the brain are exceedingly uncommon. I have seen but two in my clinic, and, with the greater aids to diagnosis, there is now no excuse for that indefinite course of iodids and mercury. I hoped to outlive this practice; at least, I have lived to see it on the wane.

\section{TYPES OF TUMORS AND THEIR TREATMENT}

We have come to recognize distinctive problems in different types of tumors. There is as much difference between an endothelioma and a glioma as between a gastric ulcer and an infiltrating carcinoma of the wall of the stomach. The former are definitely encapsulated tumors, and, taking their origin from the membranes, are readily accessible except at the base of the brain. Fortunately, they have been more frequent than the gliomas in our clinic; the proportion of the endothelioma group to the glioma group has been as 6 to 4 , in those cases in which the tumor has been exposed on the operating table. The size of the tumor is relatively unimportant (Fig. 1). Not only from the standpoint of operability, but of immediate mortality, must endotheliomas be considered quite apart from gliomas. In the latter, sharpness of definition is often lacking. By replacing normal brain tissue without adding to the volume of the cranial contents gliomas often grow to large dimensions before there are signs of intracranial pressure and the surgeon is consulted. (I must qualify this statement by admitting exceptions. Only within the year have I seen two tumors, grossly appearing as endotheliomas, sharply defined and encapsulated, but having the microscopic characteristics of gliomas [Fig. 2].)

To illustrate this distinction between the glioma and endothelioma I have compared the last ten cranial explorations for endothelioma with the last ten cranial explorations for glioma. In the endothelioma 
series, the lesion was regarded as operable in all, and there was but one fatality. In the glioma series, but one of the ten was considered operable and five of the ten patients succumbed to the mere effects of exploration. Nere exploration in the gliomat is attended with a risk peculiar to this lesion. Following the operation, an edema develops, or hemorrhage in the tumor from a ruptured blood vessel ensues. The patient, soon or immediately after the operation, may pass into a stupor, gradually deepening, until within from twentyfour to forty-eight hours the end comes (Fig. 3). One sees the brain

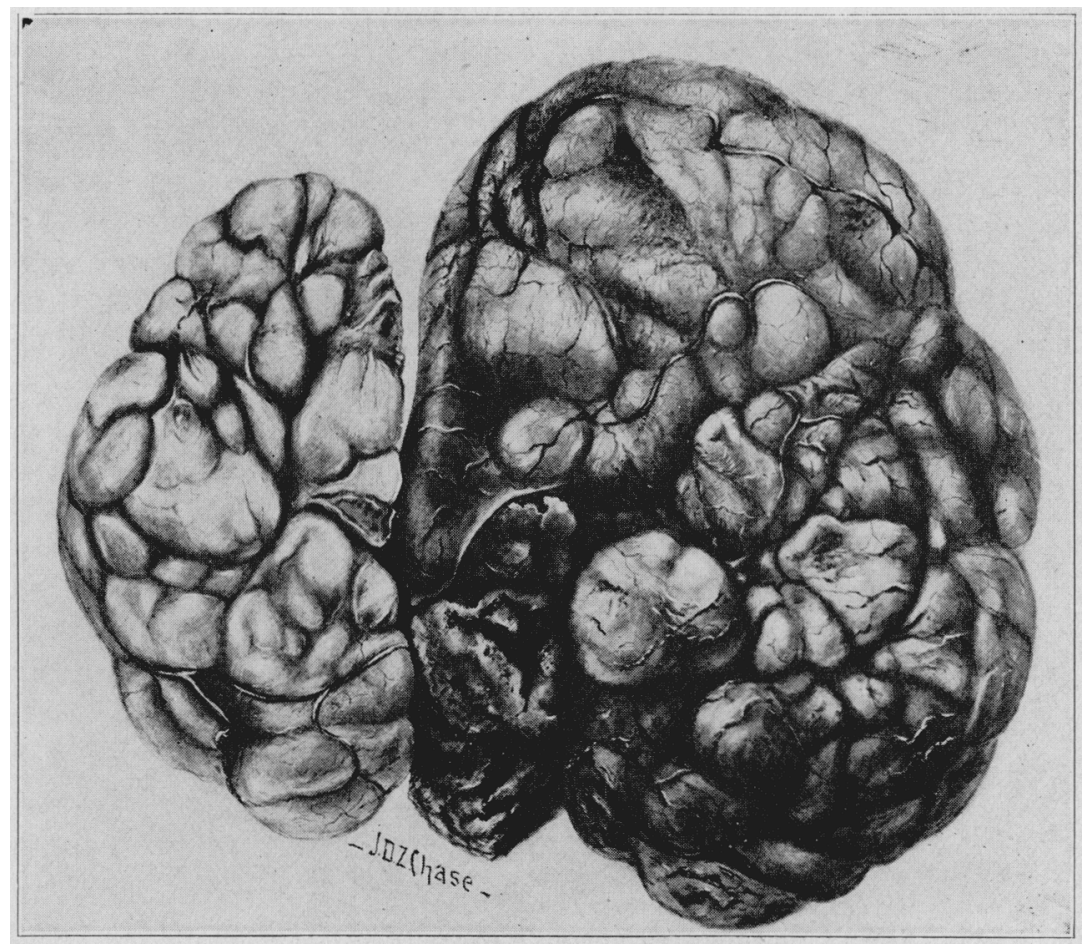

Fig. 1.-Tumor, 13 by $10 \mathrm{by} 6 \mathrm{~cm}$., after removal from frontal region of a boy, aged 6 years.

begin to swell soon after the dural flap is reflected, and it continues so to increase in bulk within the time of exploration that closure of the flap either is attended with great difficulty or is impossible. This process of edema develops in the gliomas not only when the pressure conditions are altered by reflection of an osteoplastic flap, but even by the establishment of a decompressive opening. so that one must be prepared for a fatal issue, even after an operation of itself so comparatively free from danger as the subtemporal decompression. 
It is essential that one should be able at the operating table to distinguish between a lesion which may be said to be operable and one which is inoperable. It is in this connection that judgment and experience count. The tolerance of the brain to exploration, when disturbed by conditions of increased intracranial pressure, must be appreciated. The operator can learn only by experience what constitutes operability and inoperability and must be willing and ready to recognize barriers, when confronted with tumors, to successful or satisfactory extirpation. In the consideration of the surgical problems of brain tumors, a discussion in general terms is fruitless and misleading. Differences in location and differences in tumor types are such as to demand, in an intelligent discussion of relative values, whether it be in matters of diagnosis, in matters of technic or in end-results, a subdivision or classification. Such a classification should recognize as distinct neurosurgical problems: I. Pretentorial lesions:

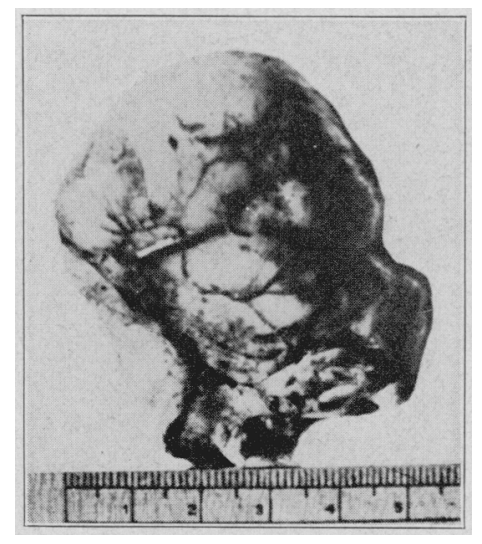

Fig. 2.-Glioma immediately after removal, showing its encapsulation.

(a) endotheliomas; $(b)$ gliomas, and (c) pituitary lesions. II. Subtentorial lesions: $(a)$ pontile angle tumors; $(b)$ "acoustic" tumors, and (c) hemispheric and intrahemispheric tumors.

A further distinction should be made in reports published under the general heading of brain tumors between those "verified" by examination of specimen removed on the operating table or at necropsy. All other cases should be considered in a group by themselves as "unverified."

PSEUDOTUMORS, SO-CALLED

I have seen in these years a group of cases, call them what you will, in which a preliminary diagnosis of tumor was made which failed to be confirmed at the operation; and yet, after the relief of pressure, 
the symptoms have subsided and the subsequent course of events has eliminated the possibility of the existence of a growth. Objections have been made to the term "pseudotumor" and its recognition as a clinical entity, and quite properly; but the existence of this nondescript group, with the possibilities not only of relief from headache and vomiting and of the conservation of vision but also of complete recovery, is, to my mind, one of the strongest arguments in favor of decompressive operations. In all probability, the underlying pathologic condition in these cases simulating tumor is a meningitis or leptomeningitis. The onset is so insidious that it is difficult to determine the source of infection, but, it has been my belief that the exanthematous and infectious fevers are in many instances the responsible factors, particularly whooping-cough, measles and influenza. The case herewith reported is an instance in point:

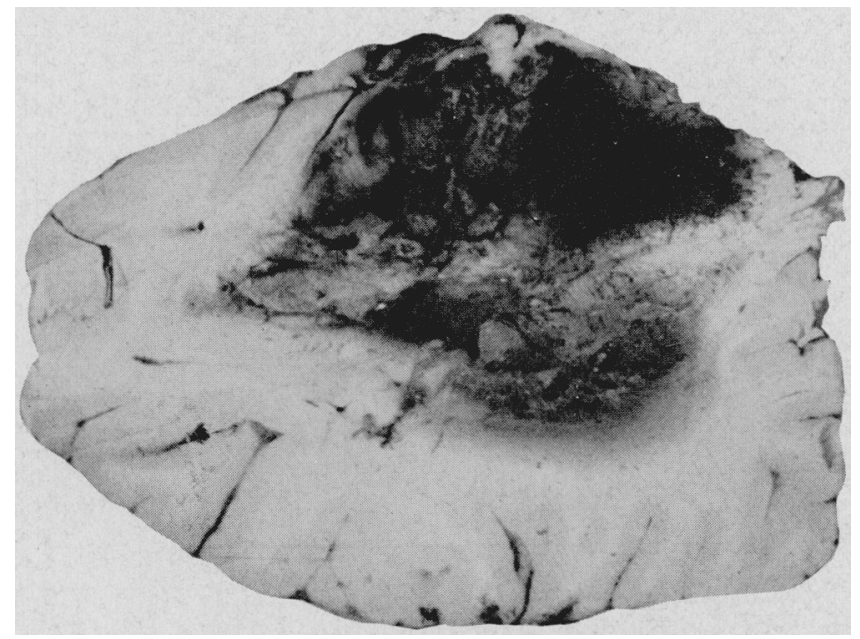

Fig. 3.-Subcortical glioma, showing vague, indefinite outline as the tumor infiltrates the surrounding tissue, a typical inoperable growth.

CASE 1.-M. L. F., aged 22 years, was admitted to the Neurosurgical Service of the University Hospital, Nov. 27, 1919. She had had influenza in October, 1918. In May, 1919, she began to complain of headache, frontal and occipital, which gradually became most intense, and in October it was associated with vomiting. Later she noted tinnitus in the right ear. She was subject to attacks of vertigo, and she could not preserve her equilibrium when standing or walking. Examination of the eye grounds revealed a papilledema of +5 diopters in each eye. A preliminary diagnosis of tumor was made; but there were not enough physical signs to warrant its localization. A right subtemporal decompression was performed, Nov. 28, 1919: there was a decided increase in intracranial pressure; but on opening the dura, a considerable amount of cerebrospinal fluid escaped and before closure of the wound the tension had subsided appreciably. 
Feb. 19, 1920, Dr. deSchweinitz reporterl that the choked disks had subsided markedly, and, Dec, 2, 1920, the choked disks had practically disappeared.

Meanwhile the patient has completed the studies of the senior class at college and has acquired a bachelor's degree. She is now symptom-free (Fig. 4).

\section{SUBTEMPORAL DECOMPRESSION}

We must revise our earlicr conception of the value and source of decompressive operations, and particularly the subtemporal decompression. Its greatest sphere of usefulness was thought to be as a palliative measure in tumors recognized as inoperable. Is a matter of fact, its greatest sphere of usefulness is really first in cases without tumors, such as the case above reported and, secondly, in cases in

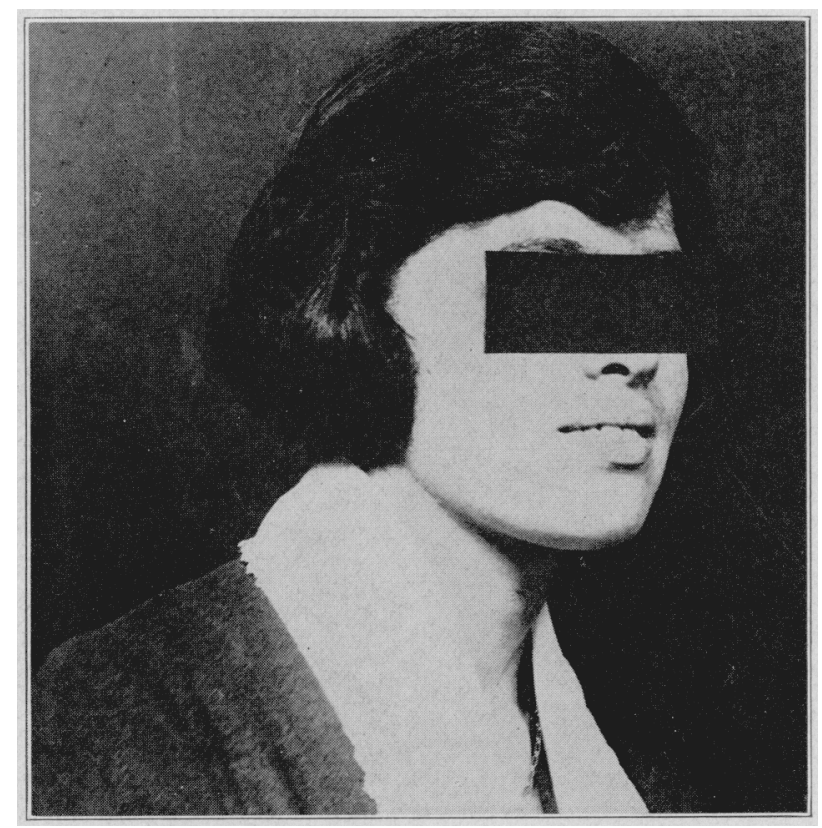

Fig. 4.-Patient, one year after subtemporal decompression. She had fully recovered from the symptoms suggestive of tumor. The underlying pathology was probably meningitis or leptomeningitis.

which the existence or location of the tumor is in doubt, and the operation is employed as one of temporary expedience, in the hope that continued observation may reveal the true nature of the lesion.

While not deprecating subtemporal decompression in tumors recognized as inoperable-one frequently must resort to it though recognizing its limitations--we must acknowledge a disappointment in the duration of the relief it affords, and the reason of this is obvious. We now 
know, what at first we did not realize, that the size of the hernia. established at the site of the opening has no relationship to the size of the growth, nor is the increase in the size of the hernia proportionate to the rate of growth of the tumor. The decompression opening affords an opportunity for the ventricles to dilate and the space presumably provided for the relief of pressure, occasioned by the growth, is soon appropriated by the dilated ventricle (Fig. 5).

As internal hydrocephalus is so frequent an accompaniment of brain tumor, no matter where its location, I frequently combine ventricular drainage by callosal puncture with subtemporal decompression. By this combination, a two-fold purpose is served. There is less likelihood of laceration of the cortex when the dura is opened under conditions of extreme intracranial pressure, and the measure of

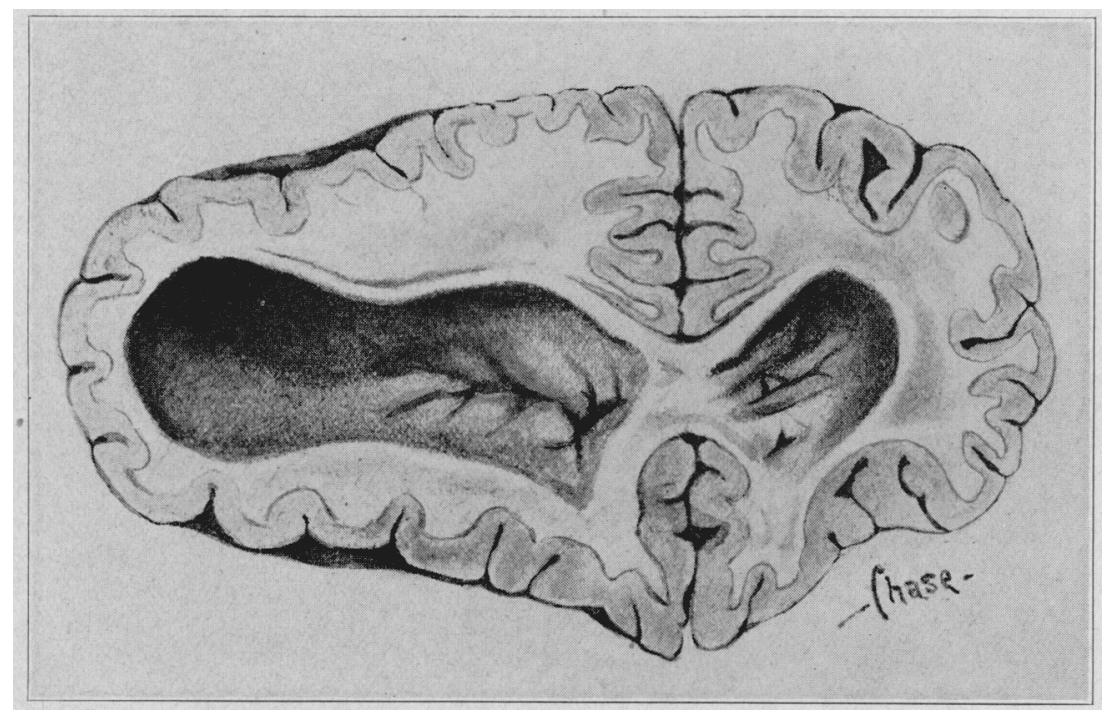

Fig. 5.-Drawing from a specimen with an internal hydrocephalus, illustrating the effects of a subtemporal decompression. Note how much of the hernia at the site of the decompressive opening is represented by the dilatation of the ventricle.

relief of pressure thus afforded is greater and of longer duration. In course of time, variable to be sure, the opening in the corpus callosum unfortunately closes.

\section{MAJOR TRIGEMINAL NEURALGIA}

It is just twenty years since the first purposeful section of the sensory root of the gasserian ganglion, after the proposal of Spiller. was performed for the relief of trigeminal neuralgia. It was not until a year's investigation in the experimental laboratory proved the 
soundness of the suggestion that I undertook the operation in my clinic. Since that time, of the $5 \mathbf{5 4}$ patients I have seen with trigeminal neuralgia, I have performed the Spiller operation 218 times and have seen the mortality reduced first to 5 per cent., then to 3.5 per cent. and now to less than 1 per cent. In the last 177 cases there has been but one operative death. In every respect, it is the most satisfactory of operations and has reached a stage of refinement that makes one feel that this chapter in neurologic surgery might be considered closed. Recently I have been able, by a modification in technic, to conserve the motor root and in so doing to prevent the atrophy of the temporal, masseter and pterygoid muscles, a matter of considerable importance, both because of the cosmetic result and

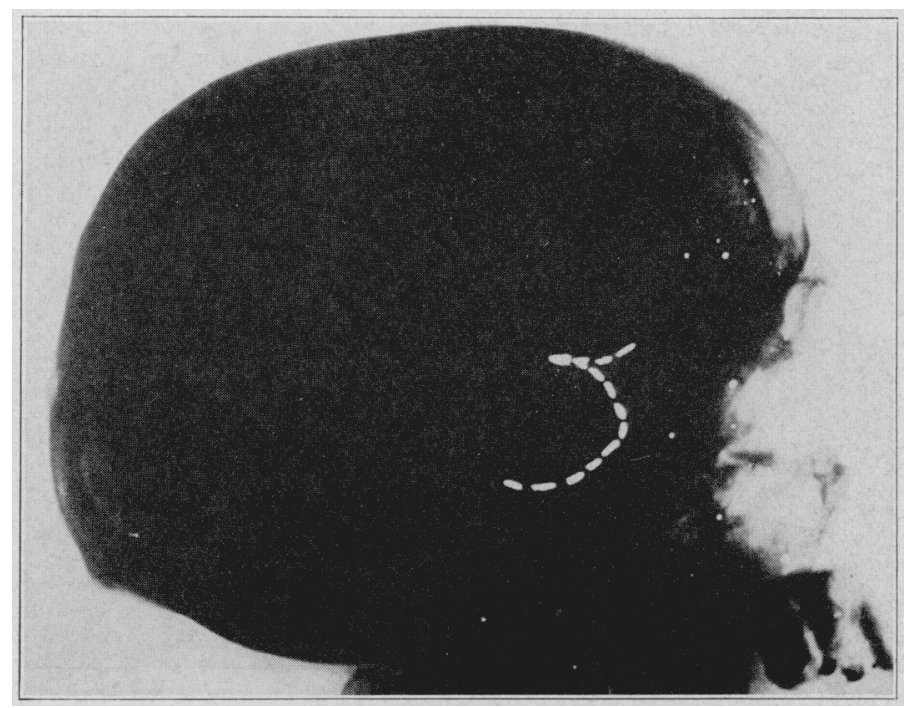

Fig. 6.-Characteristic sella deformation of a primary intrasellar lesion. The primary lesion in this case, however. was a suprasellar tumor-an endothelioma of the optic nerve. Compare with Figure 7 .

because of the greater ease with which the patient can masticate food. The time is now past when a patient suffering from this most intolerable of neuralgias should not be given immediate relief. Alcoholic injections in practiced hands give immediate, though transitory, relief. These, or the major operation, are the alternatives. There are no substitutes. Needless to say, these dogmatic statements apply only to the major or epileptiform neuralgias of the trigeminal nerve. I hear and read much about sinus disease and focal infections as etiologic factors of the major types. I can recall but two cases in which sinus disease seemed to bear any relationship to the pain, and in both these cases the clinical picture was not that of the major form. 
Not to be misunderstood, I repeat that what I have said of treatment applies to what I have called the major trigeminal neuralgia, a term we should adopt by common consent, in all dissertations or discussions, to mean that particular form of neuralgia first described by Fothergill. Its recognition is not difficult. But we must not forget that there remain, exclusive of the major form, a great many pain phenomena in the zone of the trigeminal nerve, some of which

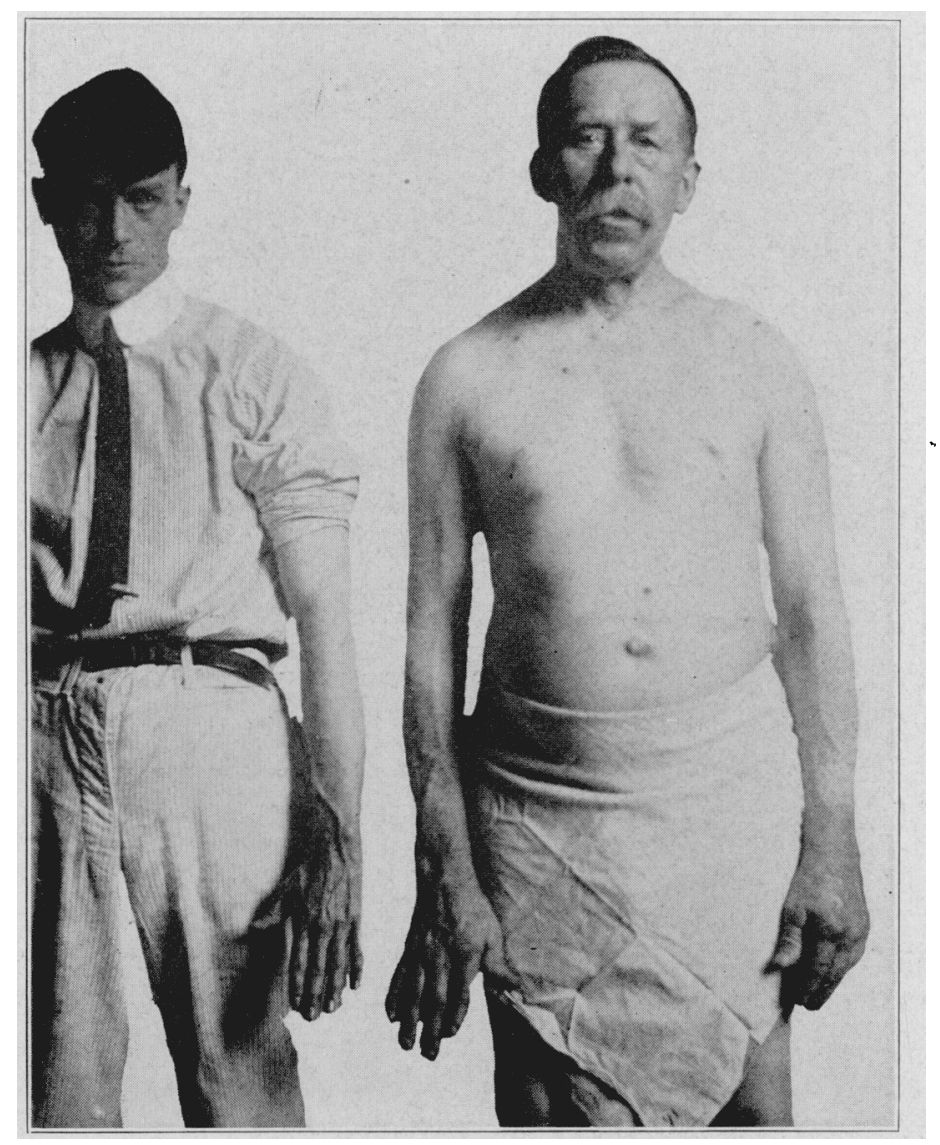

Fig. 7.-Patient (right) with acromegalic symptoms.

do not originate in any lesion of the trigeminal tract. Here is a fruitful field for investigation that brings in, among other things, the part that the sympathetic system may play. I am not referring here to the neuralgias that may arise from any infective focus, from herpes or from tumors. 


\section{SURGERY OF THE PITLITARY BODY}

As Murphy, with his button, opened up the field of gastro-intestinal surgery, so Hirsch, of Vienna, with his transsphenoidal approach first revealed the possibilities of a surgical approach to the pituitary body. Credit should be given to Schloffer, who, in 1907, performed the first successful operation on the pituitary body. We have come to recognize two methods of approach, the transsphenoidal and the transfrontal, and when I described my transfrontal method of approach, in 1912, I was disposed to advocate this as the method of choice, but since then my views have been revised. There is no doubt that when, as is so often the case, the lesion has extended well beyond the confines of the sella and is as much suprasellar as intrasellar, an adequate exposure and an attempt at radical removal are possible only by the intracranial approach.

The deepening of the sella turcica indicates downward growth, but gives no clue to the upward intracranial extension. Before the posterior clinoid processes are destroyed, the lesion has often broken

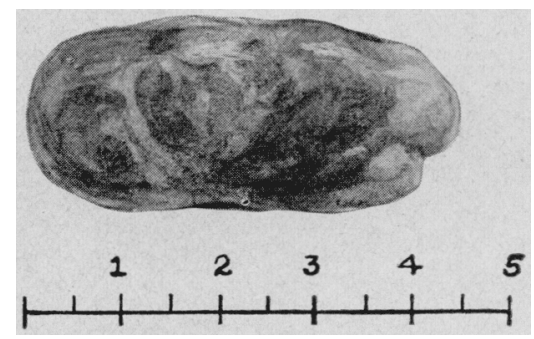

Fig. 8.-Drawing of endothelioma removed from the upper thoracic cord of a patient who had had symptoms for four years. The patient was still able to walk and there was only partial loss of sensation.

through the diaphragm and become an intracranial growth. And even a sellar decompression will not retard the growth upward. Then too, we must remember that the sellar deformation and the clinical picture may be very misleading. I have had under my care patients in whom the sellar deformation and the symptomatology were quite characteristic of a primary intrasellar lesion. And yet at operation the primary lesion was found to be a suprasellar growth. The pituitary disturbances were secondary (Figs. 6 and 7). But, admitting its theoretical advantages, the intracranial suprasellar operation is a very much more formidable procedure, and in view of the fact that in most instances life is not threatened by the lesion itself, so often a benign adenoma or a hyperplasia, the more serious of the two operations should be reserved for the final rather than the initial step in the surgical program. It is interesting to note that in the last two years we have had no fatalities following the transsphenoidal method. 
Manifold as are the clinical evidences of a disturbed pituitary function, the paramount indications for surgical intervention, after all, are disturbances of vision and headache. both pressure phenomena. The simple sellar decompression, while in no sense a radical operation, meets the immediate requirements, and, if performed before optic

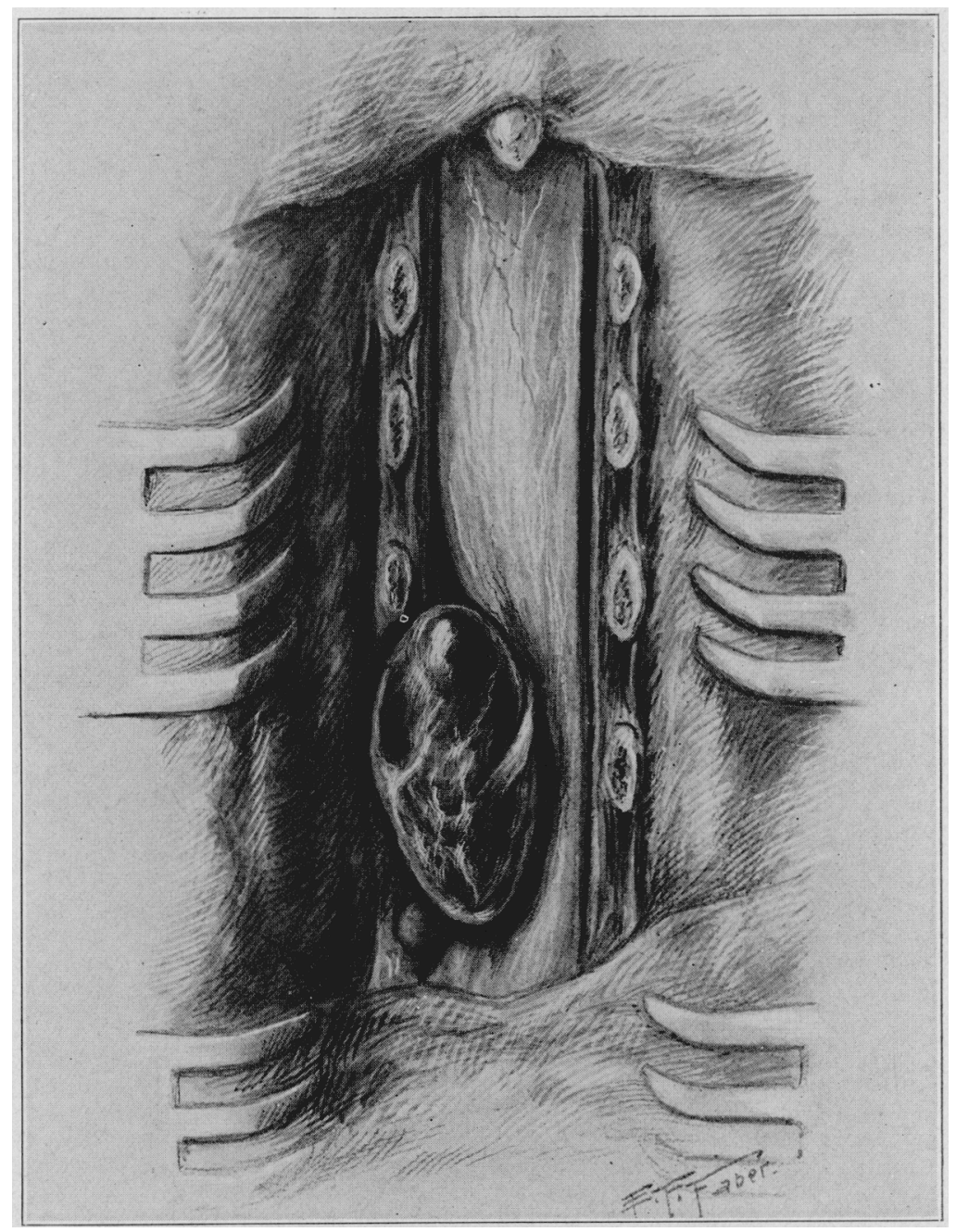

Fig. 9.--Drawing, at operation, of an extramedullary endothelioma. Three weeks after its removal, sensation was restored and the patient was able to walk.

atrophy is too far advanced, will be followed by an almost immediate restoration of the contracted visual fields to normal. And since we have found that radium and roentgen rays have a retarding influence 
on the growth of the pituitary lesion, we have in these agencies some assurance against the recurrence that often follows the sellar decompression.

TUMORS OF THE SPINAL CORD

Spinal cord tumors, for obvious reasons, present fewer difficulties as to diagnosis, localization and exploration than brain tumors. In looking over my records, I find there were but three instances in which the tumor was not found, twice because of errors in diagnosis and once because of an error in technic. The restrictions as to space within the bony canal limit the size of the tumor and at the same

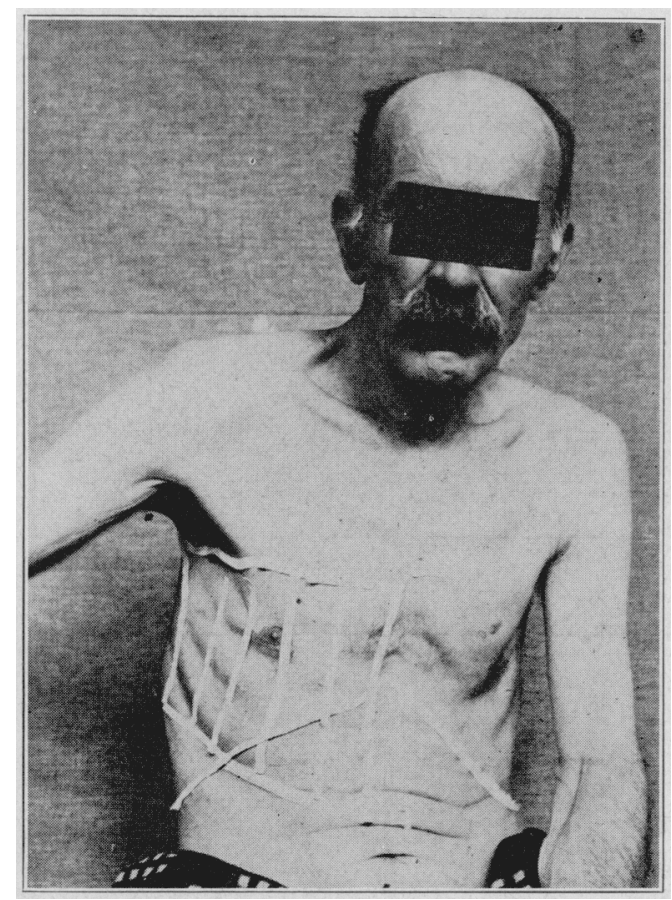

Fig. 10.-Patient after resection of the posterior roots of the seventh, eighth, ninth and tenth thoracic segments of the spinal cord. The area of anesthesia is included within the markings.

time facilitate the problem of exploration. Extramedullary tumors fortunately are more common than intramedullary growths and the majority of these are encapsulated. The relation between the various cord segments and their roots to the cutaneous segments, on the one hand, and their muscular terminations, on the other, is so definitely established that accurate localization is the rule. All these are factors which make spinal cord tumors so favorable for surgical intervention. I have been impressed with the number of cases in which the clinical 
history and the syndrome do not conforn to type, in one particular or another. It may be that pain is absent; it may be that in the history one cannot trace the three characteristic cycles: (1) of root irritation, (2) of the Brown-Séquard syndrome, (3) of vesicorectal involvement; whatever it is there are enough atypical cases to justify an appeal for earlier exploration in doubtful cases. There has been too much procrastination, while waiting for absolute and confirmatory evidence. It is surprising how the clinical picture may vary when the lesions are almost identical. I recall two recent instances in which tumors were found of almost equal dimensions. In one there was a complete paraplegia; in the other, with a clear history of four years' duration, the patient was able to walk, though handicapped more by

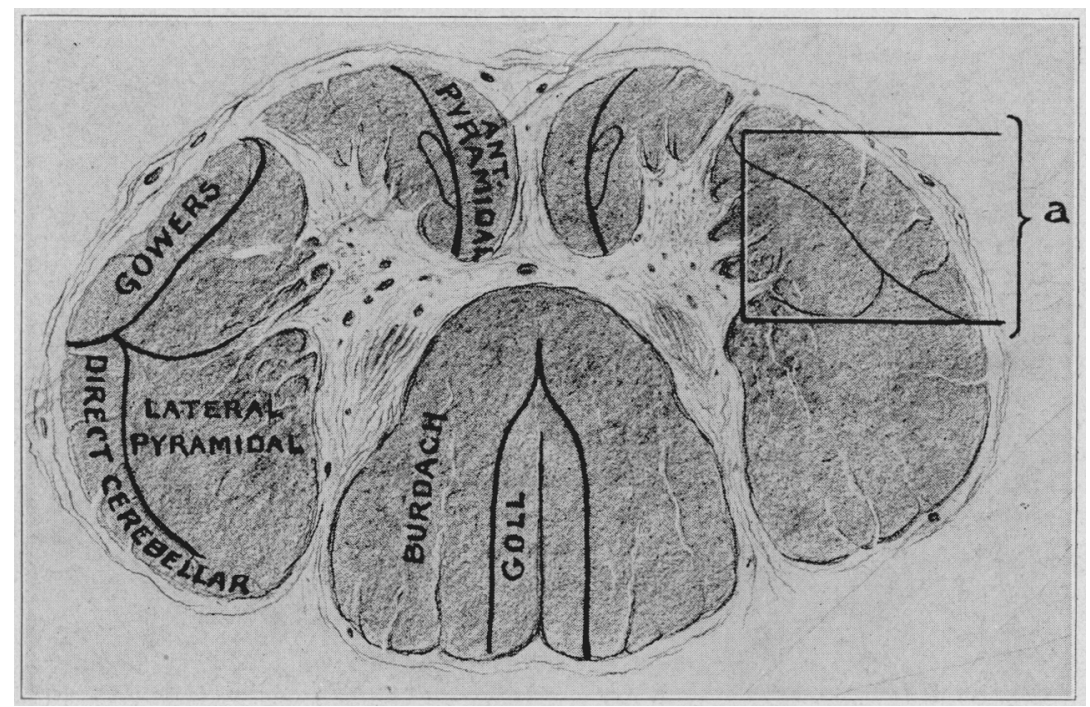

Fig. 11.-The spinal cord at the level of the sixth thoracic segment. Cutting the anterolateral columns of the cord, as described, implies section of that portion of the cord included in the area marked $a$.

spasticity than by weakness. I was in great doubt as to the propriety of operation, and yet we found a relatively large endothelioma (Fig. 8).

We have been too cautious in the spine, as in the cranial cavity, in our attitude toward exploration. Given a case of a complete or partial transverse lesion of the cord that cannot be explained satisfactorily on a basis other than tumor, even though the tumor picture is not clear, an exploratary laminectomy should be undertaken without hesitation. Too often are we called on to operate on patients with complete paraplegia because of needless hesitation and delay. The risks of operation are nil. We have had no fatalities in our entire tumor series. It was only a few weeks ago that I urged 
an exploratory operation on a patient with an advanced spastic paraplegia, who under the advice of a most competent neurologist was counseled not to be operated on, presumably because at no time had she experienced pain. A large extramedullary, encapsulated endothelioma was found and readily removed (Fig. 9).

\section{SURGERY OF THE SPINAL ROOTS}

The surgery of the spinal roots has had rather a hectic career. In 1908 , section of the posterior roots for the relief of spasticity was first proposed (Förster). By so interrupting the afferent impulses, it was thought spasticity could be controlled. Sound as the physiologic basis for this operation, the results of a fairly comprehensive application in my clinic have not justified its acceptance as a reliable procedure. There are many aspects of this problem that might be discussed in the arguments pro and con. Suffice it to say now that so many roots must be cut to obtain the desired result that the question resolves itself into a rather heroic procedure, one disproportionate to the degree of improvement in locomotion and not tolerated well by the class of patients to whom it is applicable. Be it remembered, too, that the residual muscle power cannot always be forecast and the relief of spasticity does not therefore imply a return of easy locomotion. We must pronounce the operation, therefore, for the time as sub judice. In fact, looking on the surgery of the spinal roots from every angle, we have yet much to learn. There would seem to be an analogy between section of a spinal root central to its ganglion and section of the trigeminal root central to its ganglion. and yet $I$ have been disappointed in some of my results when posterior root resection was performed for the relief of pain, the pain of intercostal neuralgia (Fig. 10), of postherpetic neuralgia, of brachial plexus neuralgia and of painful stump. The operation is not a new one; it was performed by Abbe in 1888. But the field is one in which there is an opportunity for investigative study as to the failure to secure the absolute relief that follows section of the root of the gasserian ganglion. Is it because there is a larger representation in cutaneous areas than we are wont to believe, or do the sympathetic fibers play a part, or, as has been suggested, are all the afferent fibers not contained within the posterior root? While the problem at first sight seems uncomplicated, I am convinced there are phases of it, anatomic and physiologic, that are not clearly understood.

CHORDOTOMY FOR THE RELIEF OF PAIN

In view of the unsatisfactory state of operations on the posterior roots of the cord for the relief of painful conditions, it is fortunate that a substitute measure has been found that gives greater promise 
of more enduring results. In 1912, Spiller proposed for the relief of intractable pain the division of the anterolateral columns of the cord (Fig. 11). His recommendation was based on the assumption that the fibers for pain were confined to one system and that pain sensations could not be conveyed by any other. This assumption has been confirmed in his experimental laboratory and in my clinic.

I have performed the operation six times with satisfactory results in all but one. In this case the patient had suffered incessant pain for two years. After the operation, he enjoyed absolute relief for several months, when the pain returned. As the cord cannot regenerate at the site of suture, it is difficult to account for the recurrence after a period of relief. One must assume, of course, that the columns were not completely divided. The operation, as we have planned it, calls for a section of the cord, $2.5 \mathrm{~mm}$. in its transverse and $2.5 \mathrm{~mm}$. in its anteroposterior diameters, and recently we have overcome the

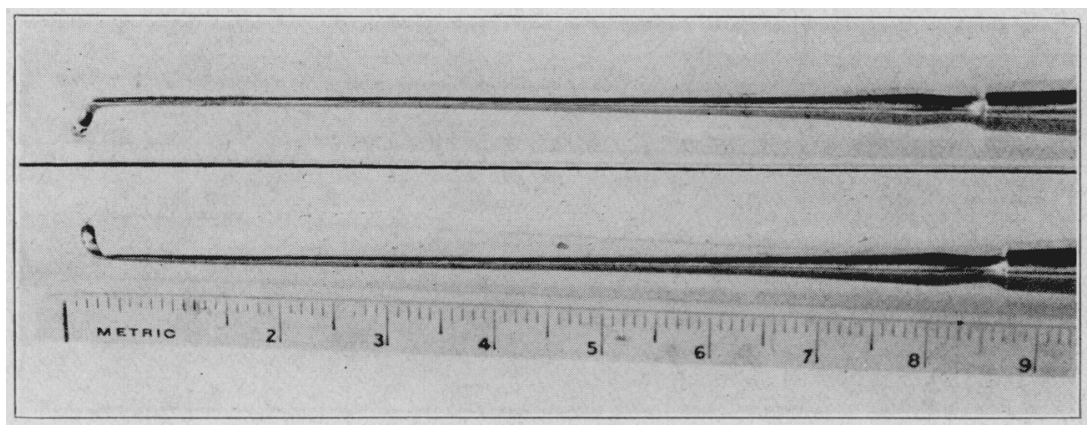

Fig. 12.-Instruments used by the author in section of the anterolateral columns of the cord. The dimensions of the mounted needle correspond exactly to the amount of cord tissue to be sectioned.

difficulty at first experienced in cutting the prescribed amount of tissue, not too much or too little, by the use of an instrument designed for this purpose (Fig. 12).

One might well ask under what conditions such an operation would be indicated: chiefly as a palliative measure to relieve the intolerable pain of malignant growths involving cord or lumbosacral plexus. Three of my cases were of this character. The other three were gunshot wounds of the spine, involving either the posterior roots or the lumbosacral plexus. I can conceive, however, of a wider application to include, possibly, aggravated forms of tabetic crisis, painful neuralgias of the thorax or lower extremities. It must be borne in mind that after this operation there is, or should be, total loss of temperature as well as pain sense. This is inevitable and must be taken into account when the operation is under considera- 
tion. The operation, of course, has a limited application; but I have been so impressed with the results that I shall continue to use it as indications arise.

\section{MATTERS OF TECHNIC}

In recording and reviewing some of the achievements in the surgery of the nervous system, I have spoken little of matters purely technical. The mechanics of spinal or cranial surgery are easily acquired and it matters little with what tools the individual surgeon prefers to remove the laminae or section the skull. The patient should be surrounded with every safeguard. In the necessarily prolonged ordeals of cranial explorations, the administration of the anesthetic must be entrusted to an anesthetist competent and accustomed to the ways of the operator and to the operation. During the war, rather from necessity than choice, local anesthesia was employed in operations for cranial injuries, and since then some surgeons have attempted to popularize it in cranial explorations for tumors and the like; but I am not at all in sympathy with this innovation, and I believe it will prove to be only a passing fad.

The control of hemorrhage is of the utmost importance, and when feasible I transfuse every patient, as a matter of routine, after a suboccipital craniectomy and after certain other prolonged cranial explorations. It is amazing how much more rapidly the patient recovers from the immediate effects of the operation and how much shorter the convalescence. As a matter of convenience and, if necessary, of economy, we have resorted to autotransfusion. If the blood picture justifies it, we remove from 500 to 600 c.c. of blood from the patient the day before the operation. The blood is citrated and kept on ice until after the operation, when it is heated and returned to the patient.

The great problem, after all, with which the cranial surgeon is almost constantly confronted is how to deal with increased intracranial tension. Unless able to cope with this, the surgeon can never be master of the situation. Successful exploration of suprasellar lesions, of angle tumors and, in some instances even, of cortical or subcortical growths can only be safely accomplished when the tension can be reduced. This is usually possible by ventricular puncture. While as a rule the ventricles are dilated occasionally, they are collapsed, and recourse must be had to lumbar puncture, though not without attending risks.

The ventriculogram may be of service in certain exceptional circumstances in this connection. On one occasion in an exploration of the left hemisphere for tumor, the tension was so great $I$ was afraid to reflect the dural flap until the tension was at least partially relieved, 
by the withdrawal of fluid from one ventricle or the other. In each attempt, I failed to find first one, then the other, ventricle and abandoned further exploration. A week later I discovered with the ventriculogram that both ventricles were collapsed. Though cognizant of the risk, I realized that what fluid there was in the subarachnoid space would have to be removed by lumbar puncture. Accordingly, at a second sitting, 50 c.c. of fluid was withdrawn and the tension so relieved that the subsequent exploration and removal of the growth was easy of accomplishment. Originally, Dandy introduced the ventriculogram as a means of localization; but thus far it has not aided me in establishing the location of a growth not indicated by other signs.

As a means of controlling increased intracranial pressure during exploration, the intravenous use of saturated salt solution has been proposed. In the laboratory, Weed and McKibbon observed, as a result of tissue dehydration, a shrinkage in brain volume. Already one or two isolated instances have been reported ${ }^{1}$ of rather startling effects. I regret it has not been of service in my hands. The method is not unattended with risk so that it is far from being regarded as a recognized or approved procedure.

\section{CONCLUSION}

I have touched but briefly on subjects that are now commanding attention. There have been notable achievements on the one hand and sorry failures on the other. For the coming generation, there are many fields still open for investigation, many problems still unsolved. The shortcomings and disappointments should stimulate, rather than discourage. That there is a wide enough scope for investigative pursuits to justify the recognition of neurosurgery as a specialty no one will question. Certain it is that the promise of the future lies in the hands of those who will give it their undivided attention.

1. Sachs, Ernest, and Belcher, G. W.: Use of Saturated Salt Solution Intravenously During Intracranial Operations, J. A. M. A. 75:667 (Sept. 4) 1920. 